\title{
The Power of Academic Research for Innovation in Practice and Policy: Systemic Review of Literature
}

\author{
Article by Bala Ibn Shehu Uthman \\ MRSPH, Member APHA, Nigeria \\ E-mail: balee67@yahoo.com
}

\begin{abstract}
The aim of this paper was to explore and present the impact or power of the academic research for innovation in practice and policy, that is, the academic research collaboration in the progress of policy in government and innovation in professional practices with particular emphasis on northern Nigerian region. It is a systemic review type of study design.

As a matter of fact, universities and other higher institutions like polytechnics schools, have been serving our societies for virtually a thousand years and we have no doubt in our minds that over that period of time, universities, schools of polytechnic, colleges of higher education and the world have undergone significant transformation mainly due to advancement in research that influence policy formulation and its implementation.

It is obviously clear to everyone that, the world is now more complex, more interwoven or inter-connected and changing more rapidly and that we also live in an environment that is coerced by news cycles, passing manners and uncertainty in the futures. Moreover, social structures are changing, as well as values and attitudes. There are also competition that is growing, people are increasingly mobile and the global economic becomes centre of gravity that is changing at a speed not seen before. As such, governments have to address such problems as climate change, potential pandemics of diseases and food insecurity that are global in scope and require a coordinated global response. These are achieved through research (both academic and other form of researches)

Natural and man-made disasters are becoming more common and their consequences greater. People everywhere feel under pressure. Change is inevitable and one of the important roles of universities and other higher institutions has been to make some of these changes possible through mostly academic researches that create new understanding, new technologies and the potential for action; and by providing a store of knowledge and capabilities that society as a whole has been able to draw upon.

In this paper, therefore, the author reviewed some papers written by other authors on the subject and then expressed the situation obtainable here in Nigeria, the gaps and challenges in the use of academic research in policy development and practice in the area under review. Some recommendations were also made.
\end{abstract}

Keywords: Academic Research, Innovation, Growth and Development, Policy Development.

\section{Introduction}

Academic research is a type of research that is done in an academic environment such as universities, schools of polytechnic and colleges of higher education. Generally speaking, research is a logical and systematic process of searching for knowledge or new ideas on a particular topic, events behaviors or theories.

The objective of this paper was to explore and present the impact or power of the academic research for innovation in practice and policy, that is, the academic research collaboration in the progress of policy in government and innovation in professional practices with particular emphasis on northern Nigerian region. It is a systemic review type of study design.

As a matter of fact, universities and other higher institutions like colleges of education and schools of polytechnics, have been serving our societies for virtually a thousand years and we have no doubt in our minds that over that period of time, universities, schools of polytechnic, 
colleges of higher education and the world have undergone significant transformation mainly due to advancement in research that influence policy formulation and its implementation.

In the modern world, research has become an integral part of the world's educational status and could be done in all specializations, field of line at all stages. This means that, the significance or importance of research in the modern world is so obvious that even the government of many countries or nations today invest huge sum of money on doing research and encourage conducting research in areas where research would bring about changes, growth, development, invention-innovation or renovation.

Innovation is said to be the process by which new products, processes, methods or services are created. Innovation provides added value for end users by providing better or cheaper functionality than previous options. Moreover, innovation combines changes in technology, business models, organization etc. The basic idea may be a new technical solution, a new business model or a change in organization. More often than not, however, changes in all aspects are required in order to realize the full potential.

This paper reviewed some other papers written by other authors on the subject and then expressed the situation obtainable here in Nigeria, the gaps and challenges in the use of academic research in policy development and practice in the area under review were also discussed and some recommendations were made by the writers of the papers. Some of the constraints of the academic research in Nigeria include inadequate and irregular funding, poor motivation, poor or obsolete research infrastructure, brain drain and rising workload resulting from deteriorating staff/student ratio. These constraints have also generally led to low research productivity".

Recommendations made included: The Nigerian Government should have adequate budget and release sufficient funds for research with particular emphasis on innovative or interdisciplinary research as against either surveys, impact analyses, appraisals, evaluation studies or analytical studies. The federal government should expose to a wide range significant number of technological opportunities so as to address its human development and research for innovation challenges. Technologies such as information and communication technologies, biotechnology and nanotechnology can be harnessed and applied to increase food production, fight diseases such as malaria, tuberculosis and HIV/AIDS, and increase economic competitiveness of the country. And lastly, Nigeria government should strengthen and ensure the availability of the National Science Research Technology and Innovation Fund (NSRTIF) which the country have already opted to create for the development of science and technology in the country.

\section{What is academic research?}

Generally speaking, research could be defined as an active, coherent, diligent, logical and systematic process of searching for knowledge, inquiry for new ideas or useful information on a particular topic, behaviors, events or theories.

Writing on academic research, Betsy Beacom - an eHow Contributor, wrote "Academic research which is done in an academic environment, such as a university is presented in writing using a specific format according to a style guide such as that of the American Psychological Association (APA).”

Furthermore, writing on academic research trends and futures scenarios, Stéphan Vincent wrote to say that "academic research is understood as research and development (R\&D) undertaken in the higher education sector, including universities, polytechnics, etc., and research centers that have close links with higher education institutions.”

Research can, therefore, be seen as a process of finding solutions to problems after a thorough study and analysis of the situational factors.

\section{The purpose and value of academic research}

Betsy continued to write on the importance of academic research where he mentioned that

"The purpose of academic research writing is twofold: 
I. To explain the goals, methodology and results of academic research, and

II. To analyze and interpret the findings".

The main purposes of research are, therefore, to predict, describe, explain or control an intervention, theory or program. This means that, research is being conducted to foretell a phenomenon that will result or occur at time $\mathrm{Y}$ from information at an earlier time $\mathrm{X}$, to describe natural or social phenomenon, such as its activity, change over time, relationship to other phenomena, to describe or predict consequences, and know how to intervene to change those consequences or to undertake such approaches that may include experimental design and evaluation research.

In the modern world, research has become an integral part of the world's educational status and could be done in all specializations, field of line at all stages. This means that, the significance or importance of research in the modern world is so obvious that even the government of many countries or nations today invest huge sum of money on doing research and encourage conducting research in areas where research would bring about changes, growth, development, invention-innovation or renovation.

\section{The concept of research for innovation and growth}

An "innovation is the implementation of a new or significantly improved product (good or service), or process, a new marketing method, or a new organizational method in business practices, workplace organization or external relations” Oslo Manual (2005).

Research and Development was defined as "creative work undertaken on a systematic basis in order to increase the stock of knowledge, including knowledge of man, culture and society, and the use of this stock of knowledge to devise new applications”, QECD Frascati Manual (2002).

As such innovation is, therefore, the process by which new products, processes, methods or services are created. Innovation offers added value for end users by providing better and/or cheaper functionality than previous options. Moreover, innovation combines changes in technology, business models, organization etc. The basic idea may be a new technical solution, a new business model or a change in organization. More often than not, however, changes in all aspects are required in order to realize the full potential. QECD (2014)

Charlotte Brogren - Director General of VINNOVA in April 2014 wrote as a forward in a report titled 'Innovations and new technology', “The ability to create and benefit from innovation plays a central role in income, employment and quality of life. Not only do innovations contribute to prosperity, they are increasingly important in addressing the many social challenges created by our quest for prosperity". Research-based competence is said to play an increasingly important role in the development of innovations and new technology.

According to Charlotte, "We need to think of innovation not as a sudden flash of inspiration, but as a long process of searching, experimenting and learning”. Charlotte also believes that publicly funded research can contribute in many different ways and at all stages of the innovation process. For this to become a reality requires policies that allow for continuous interaction so that researchers and companies can learn from each other.

At the end, it is obvious that much of the rise in living standards is due to innovation as this has been the case since the Industrial Revolution. Today, innovative performance is a crucial factor in determining competitiveness and national progress. Moreover, innovation is important to help address global challenges, such as climate change and sustainable development.

\section{The concept of policy}

Policy is often thought of as decisions taken by those with responsibility for a given policy area - it may be in health or the environment, in education or in trade. The people who make policies are referred to as policy makers.

Policy may be made at many levels such as federal or local government, in a multinational company or local business, in a school or hospital. A specific group of decision makers who 
have high positions in an organization, and often privileged access to other top members of the same, and other, organizations are sometimes referred to as policy elites. For example, Policy elites in government may include the members of the Prime Minister's Cabinet, all of whom would be able to contact and meet the top executives of a multinational company or of an international agency, such as the World Health Organization (WHO).

Policies are made in the private and the public sector. In the private sector, a group of diverse companies under common ownership and run as a single organization may establish policies for all their companies around the world, but allow local companies to decide their own policies on conditions of service. For example, corporations such as Anglo-American and Heineken introduced anti-retroviral therapy for their HIV-positive employees in Africa in the early 2000s before many governments did so. However, private sector corporations have to ensure that their policies are made within the confines of public law, made by governments. Sometimes policy is called a program: the government's school health program may include a number of different policies: precluding children from starting school before they are fully immunized against the major vaccine-preventable childhood diseases, providing medical inspections, subsidized school meals and compulsory health education in the school curriculum.

Having known the concepts of academic research, innovation, growth and policy in government and private organization, let us now look into the relationship between these concepts. Ideally, academic research writing should have basic ingredients as organization, contents, expression and accuracy.

\section{Organization and expression of an academic research writing}

Basically, academic research writing should have a formal organizational structure. It usually begins with an abstract that summarizes the contents and helps the reader decide whether to read the entire document or not. This is then followed by the introduction which outlines the research problem, the main goal in addressing the problem and the author's stance. A literature review follows the introduction, where the author demonstrates how the research project fits into existing literature on similar topics. The methodology section then describes any surveys, laboratory experiments or other means by which data was gathered. Hence, results of the research are then presented as quantitative or qualitative information. This is then followed by a discussion section which addresses what the author learned from the research. The conclusion elaborates on the discussion and allots significance to the research findings in the context of existing research. References are mandatory so as to give credit to sources used.

\section{Content and accuracy of an academic research}

This entails using the information and findings in writing academic research. Prior to the beginning of the research project, a proposal in writing may be presented to a committee to obtain approval for the project. This proposal as earlier mentioned should include an abstract, introduction, literature review, and there should also be a description of the proposed research project and expected outcomes or results. However, after the research and writing are completed, it may be presented to a committee as part of the process of earning an advanced degree or published in a peer-reviewed academic journal as the case may be.

It is worth notice that writing an academic report or paper involves activities like thinking about a topic, reading about the topic in mind, making a case about the topic and eventually writing about the scholarly topic. In most cases, the idea is to get readers of the research work to see the topic in a new light. It should also be note that academic report differs from other types of reports one may have done (perhaps ones written for high school assignments) in that it presents both researched facts and researchers own assessment. 


\section{The systemic review of the existing literature}

Having these brief ideas about academic research writing, I would look into some of the papers written on academic research and review findings by the other authors. Four papers were reviewed by me, two indigenous that is written by the Nigerians or people working in the Nigerian's higher institutions and two other non indigenous papers, which were not written in the Nigerians context.

The Two papers that were written in the Nigerian context were titled:

1. “An Appraisal of Research in Nigeria’s University Sector" (2012) written by A. K. Yusuf from Department of Basic and Applied Sciences, Hassan Usman Katsina Polytechnic, Katsina state Nigeria (Northern Nigeria), and

2. "Research and Innovation Strategies for Economic Competitiveness and Industrial Growth: Lessons for Nigeria.” (2014) written by E.H. Kwon-Ndung, L. Kwon-Ndung and J. Migap of Department of Botany, Federal University, Lafia, Department of Political Science, Nasarawa State University Keffi and Department of Economics, Federal University Lafia respectively all of Lafia. Nasarawa State (Northern Nigeria).

The other two papers not written in the Nigerian context were titled:

1. "Innovations and new technology - what is the role of research? Implications for public policy" (2014) written by L. Elg - VINNOVA

2. "Innovation and Growth-Rationale for an Innovation Strategy" (2007) by Organization for Economic Co-Operation and Development (OECD).

\section{Significance of academic research work}

Research significance is to clearly state why a research is important, what the benefits of the research would be and how the research work will contribute to knowledge in the concerned field. So the basic benefits of a research include changes in current practice, a new perspective on an old issue or other benefits to the community. The researcher may need to indicate why it is significant and how the research advances understanding of the issues under discussion.

On this issue, A.K.Yusuf (2012) (Please permit to be addressing henceforth as 'Malam Yusuf') wrote: "The role of higher education research in national development cannot be over emphasized. However, research in Nigeria's institutions of higher learning comprising the universities, polytechnics and colleges of education has yet to make a real impact on the technological advancement of the country and the socio-economic well-being of its citizenry."

More over E.H. Kwon-Ndung et al highlighted that "One of the leading unrealized opportunities in Nigerian industrial organizations is the full influence of research ideas and knowledge to transform business products and processes into long-term innovation.” They further wrote to say that "Business research and innovation contribute significantly to improvement in enterprise productivity and quality and in the integral components of business strategy and success.

In essence, research is important both in scientific and nonscientific fields. This is because in our life, new problems, events, phenomena and processes occur every day. As such, practically implementable solutions and suggestions are required for tackling new problems that arise. This signifies importance of research to our everyday life. It also implies that Scientists have to undertake research on our daily problems and find their causes, solutions, explanations and applications. Precisely, research assists us to understand nature and natural phenomena. Research is, therefore, the fountain of knowledge and provides guidelines for solving problems.

So absorbing to a considerable degree from these published literatures, there are enormous benefits of continual research and innovation on national economies, and one could proffer recommendations on how Nigeria could key into this concept to promote its economic competitiveness at the global level. 


\section{Academic research and policy development}

Reinhilde Veugelers (2014) wrote in a paper titled "The contribution of academic research to innovation and growth" that the most salient policy recommendations that stems from the analysis is that policy makers looking for ways to improve the contribution of universities to innovation based growth, should take a long-term perspective for developing an industryscience eco-system, avoiding the temptation of quick "success stories". Policy makers should be more "innovative" in their search for effective policy interventions, venturing beyond the classic spin-off and incubator programs. At the same time, they should be more serious about evaluating their new and existing instruments. To progress, policy makers should support more systematic data collection and analysis on the various pathways for universities' contribution to economic prosperity".

One clear example of a policy issue in research is the fact that research forms an integral part of public health services, it helps in giving a quality and modernized form of health services to the public. However, despite the fact that, research is meant to help in effective decision making and in making public health policies that would improve a population health, the results of many research works are usually not or underutilized by the people that are supposed to use them. This fact was clearly stated by A.K. Yusuf (2012) where he pointed out that "research in Nigeria's institutions of higher learning comprising the universities, polytechnics and colleges of education has yet to make a real impact on the technological advancement of the country and the socio-economic well-being of its citizenry.”

Moreover, even in some developed countries, the government in some cases sponsored research works and may not fully utilized the results in making effective decision or policies; a very good example is that of Reinhilde Veugelers (2014) who wrote in a report titled "The contribution of academic research to innovation and growth" that "When looking at the evidence for Europe, there is a general lagging behind relative to the US, particularly on academic patenting and university spin-offs. Patenting and licensing is only two of a number of pathways for the transfer of knowledge from universities to industry, and perhaps not even the best forms. Student \& researchers' mobility from academe to industry is a critical mechanism to transfer knowledge from the university to industry, particularly when the knowledge to be transferred is hard to codify and is embodied in human capital as is the case for science-based knowledge. Although this is an area of great importance to the study of the innovation process, only recently research has started to attempt to trace researchers' intersectoral mobility". However, this project work that was carried out by Reinhilde has received funding from the European Union's Seventh Framework Programme for research, technological development and demonstration under grant agreement no. 290647.

Unfortunately, such is not the case in some developing countries, where the leaders (decision or policy makers) are only concern with what would promote their personal or political interests. In some developing countries, often an individual or donor agency may undertake a good research with marvelous results and very good recommendations that if implemented would change or improve a particular populations' health status or cause considerable economic or industrial growth, but the most painful part of it, these would only remain on paper without real implementation of the said recommendations and that means waste of resources in undertaking a research work that its results would not help in yielding anything positive. This is also supported by the paper written by E.H. Kwon-Ndung et tal (2014) that "One of the leading unrealized opportunities in Nigerian industrial organizations is the full influence of research ideas and knowledge to transform business products and processes into long-term innovation”.

\section{Changes in academic research and its application in different fields or professions}

What is changing in academic research has been disclosed by Stéphan Vincent-Lancrin (2006) where he asked the following very vital questions: "What is changing in academic research? What has changed over the past decades and what might change in the coming 
ones? Could the research mission of universities be carried out in slightly or radically different ways in the medium term? In his paper titled "What is changing in academic research? Trends and futures scenarios" he tried to answer the questions by dividing his paper into eight (8) sections as follows:

In the first section of the paper it was mentioned that research and development (R\&D) has grown significantly during the two past decades within the Organization for Economic Cooperation and Development (OECD) area, which accounted for about $80 \%$ of all R\&D expenditures in the world (OECD, 2005a). The paper further highlighted that "gross domestic expenditure on R\&D amounted on average to 2.3\% of GDP (Gross Domestic Product) in 2003, against $1.9 \%$ in 1981. In real terms (that is, controlling for inflation), R\&D expenditures have more than doubled between 1981 and 2003".

The second section of the paper pointed out that with some variations across countries, the business sector carries out and funds the bulk of R\&D in the OECD area. Giving example as in 2003, Greece, Poland, Portugal and Turkey were the only countries reporting more R\&D expenditures in the higher education than in the business sector. The prominence of the business sector has sharpened over the past decades. Between 1981 and 2003, the share of $R \& D$ performed by the business sector has risen from $65.4 \%$ to $67.7 \%$ of the total R\&D effort in the OECD area. Business expenditures on the performance of R\&D have risen from 1.26 to $1.53 \%$ of GDP that is by $141 \%$ in real terms. The business enterprise sector has also increased its financing of R\&D from 1 to $1.39 \%$ of GDP between 1981 and 2003. This increasing performance an $d$ funding of $R \& D$ by businesses is one of the most significant trends of the past decades - explaining to some extent why OECD economies are often described as increasingly knowledge-based economies (Foray, 2004; Boyer, 2002).

So, the first section of the paper as shown above documents the growth in funding and output, while the second section shows that academic research can be characterized by its large proportion of basic research.

The remainder of the paper focused on academic research, where parallel trends were observed. It was highlighted that government funding, although the mode of allocation of public funding has changed in the past twenty years (section 3). A noteworthy trend has been the rise of the private funding of higher education and performance of basic research by the non-academic sectors (section 4). Internationalization of academic research has grown significantly (section 5), while a new attitude of civil society towards research (section 6) and new computing and networking opportunities offered by information and communication technology (ICT) are emerging as new driving forces for the future of academic research (section 7). The last section brings all these trends together by proposing four futures scenarios for discussion (section 8).

The application of research in different settings such as public health would never be over emphasized as research can lead to new contributions to the existing knowledge, and only through research is it possible to make progress in a field like public health. Research is indeed civilization and determines the economic, social and political development of a nation. The results of scientific research very often brought or force a change in the philosophical view of problems which extend far beyond the restricted domain of science itself. Research is therefore the fountain of knowledge and provides guidelines for solving problems in public health as well as in other disciplines.

\section{Constraints or problems and challenges of academic research in nigeria}

Almost every time and in our everyday life, we appreciate the use of research in supporting and providing new ideas and knowledge for example about our health and what we can do to improve it. Research provides basis for many government policies such as research on the needs and desires of the public and on the availability of revenues to meet the needs or helps a government to prepare a budget. Unfortunately there are many constraints that affect research among which were mentioned by A.K.Yusuf (2012) where he highlighted that "Constraints hampering the realization of research goals in the higher education sector include inadequate 
and irregular funding, poor motivation, poor or obsolete research infrastructure, brain drain and rising workload resulting from deteriorating staff/student ratio. These constraints have also generally led to low research productivity”.

Other challenges affecting research in Nigeria were also highlighted by E.H. Kwon-Ndung et tal (2014) where they wrote "Several factors have been cited for the poor level of research and innovation in Nigeria, such as:

I. Neglect of the education sector.

II. Lack of emphasis on science and engineering courses.

III. Most manufacturing firms were government owned and does not engage in productive R\&D to develop new products and processes that would enhance its competitiveness since they were mostly finance by government subventions:

IV. The few privately owned firms are in most cases subsidiaries of foreign multinationals and does not encourage local R \& D, they only implement production strategies and policies emanating from head-office which in most cases does not favour the development of local research development.

V. Poor funding of research institutions.

Barriers to the use of research evidence, however, are said to include: decision makers' perceptions of research evidence; the gulf between researchers and decision makers; the culture of decision making; competing influences on decision making; and practical constraints.

Suggested, but largely untested, ways of overcoming these barriers included: research targeted at the needs of decision makers; research clearly highlighting key messages; and capacity building. There was little evidence on the role of research evidence in decision making to reduce inequalities.

\section{Recommendations}

- The Nigeria government through the Ministry of Science and Technology to develop a more concise, robust and workable Science, Technology and Innovation (STI) policy which is expected to respond to the dictates of globalization, changing business environment and new/emerging technologies and thus provide for effective funding of R\&D.

- The Nigerian Government should have adequate budget and release sufficient funds for research with particular emphasis on innovative or interdisciplinary research as against either surveys, impact analyses, appraisals, evaluation studies or analytical studies.

- The federal government should expose to a wide range significant number of technological opportunities so as to address its human development and research for innovation challenges.

- Technologies such as information and communication technologies, biotechnology and nanotechnology can be harnessed and applied to increase food production, fight diseases such as malaria, tuberculosis and HIV/AIDS, and increase economic competitiveness of the country.

- Nigeria government should strengthen and ensure the availability of the National Science Research Technology and Innovation Fund (NSRTIF) which the country have already opted to create for the development of science and technology in the country.

- E.H. Kwon-Ndung et tal (2014) recommended that "for Nigeria to achieve macroeconomic development and assume its rightful position among the committee of emerging economies, it needs to reorder its priorities by committing more funds to R\&D activities to meet UNESCO standards of having at least $1 \%$ of GDP committed to R\&D as well as faithfully implement the National R\&D Fund”. 


\section{Conclusion}

It was concluded by the study that to more effectively implement research, action is required by decision makers and researchers to address the barriers identified in the said systematic review. There is an urgent need for evidence to support the use of research evidence to inform decision making and to reduce inequalities. It should be sufficiently recognized that innovation can originate anywhere and increased education and economic growth have improved the capacity of developing countries to offer new products and services.

As right put by E.H. Kwon-Ndung et tal (2014) that "It is not a coincidence that countries such as USA or Japan are the world's top economies because their allocation of resources into creating innovation is massive. It obviously indicates that innovation is the key driving growth and prosperity. Approximately 50\% of US annual GDP growth is attributed to increases in innovation. For the past two centuries, the US has been the world-leader in developing innovative products and services. Innovation therefore is the engine for the economic growth as it makes a great contribution in economic growth and development in an economy or the world as a whole. In the words of American Entrepreneur and Apple coFounder (Steve Jobs), "Innovation clearly distinguishes between a leader and a follower". We humbly and completely concur to this".

\section{Acknowledgements}

I wish to acknowledge the support I got from my new student coordinator Ms T, Gowri of Texila American University, my project guide Dr Muhammadu Nasiru Isyaku Provost College of Education Azare Bauchi State Nigeria. I also wish to acknowledge the writers of the papers I reviewed such as A.K.Yusuf, E.H. Kwon-Ndung, L. Kwon-Ndung and J. Migap. I also acknowledge the non Nigerian writers that wrote on this field such as Stéphan VincentLancrin (OECD-CERI), Prof. Ilberto Stocchi (Rector of "Carlo Bo" University) and many others that I would not be able to mention them all here.

\section{References}

[1] A.K.Yusuf (2012), “An Appraisal of Research in Nigeria’s University Sector”. JORIND 10 (2), June, 2012. ISSN 1596 - 8308. www.transcampus.org./journals, www.ajol.info/journals/jorind

[2] E.H. Kwon-Ndung et al (2014), "Research and Innovation Strategies for Economic Competitiveness and Industrial Growth: Lessons for Nigeria”. European Journal of Business and Innovation Research Vol.2,No.6, pp.56-76, December 2014

[3] Stéphan Vincent-Lancrin (2006), "What is changing in Academic Research? Trends and Futures Scenarios". Forthcoming in the European Journal of Education, 41, 2, June 2006.

[4] Group of Eight (2013), "The Role and Importance of Research Intensive Universities in the Contemporary World”(Discussion Paper). The Group of Eight Group of Eight House Level 2, 101 Northbourne Avenue Turner ACT 2612. www.go8.edu.au

[5] Prof. Ilberto Stocchi et al (2015), "Increasing the Power of Academic Research through the Insitutional Research and Innovation Development on Macroregione Adriatico-Ioniana”. E-ISSN 22814612 ISSN 2281-3993 Academic Journal of Interdisciplinary Studies MCSER Publishing, Rome-Italy Vol 4 No 2 S2 August 2015

[6] OECD (2007), "Innovation and growth rationale for an innovation strategy". Organization for Economic Co-Operation and Development.

[7] Lennart E, - VINNOVA (2014), "Innovations and new technology - What is the role of Research? Implications for Public Policy”. VINNOVA - Swedish Governmental Agency for Innovation Systems / Verket för Innovations system ISBN 978-91-87537-16-5

[8] Betsy Beacom (2016) eHOW, "Definitions of Academic Research and Process of Writing Academic Research”. http://www.ehow.com

[9] Dr. Donald (2015), Study Modules "Research Methodology". Master Public Health, School of Public Health, Texila American University. 